\title{
The Effective Way in Answering the IPSS: Patients Themselves or with the Physician?
}

\author{
(1) Hasan Turgut 1,2, (1) Güner Kemal Özgür2 \\ ${ }^{1}$ Faculty of Health Science, Avrasya University, Trabzon, Turkiye \\ 2 Medicalpark Karadeniz Hospital, Clinic of Urology, Trabzon, Turkiye
}

\section{What's known on the subject? and What does the study add?}

The International Prostate Symptom score (IPSS) is an evaluation form used in the diagnosis of benign prostate hyperplasia in clinical practice. It has been translated into Turkish and thus may not be fully understood by patients. In this regard, there may be differences in the treatment of the patients. When the IPSS form was filled with the help of a physician, the results were different from those of forms that were filled by the patients themselves. Based on our clinical experience, the IPSS form answered with the help of a physician gives more useful results in treatment regulation. This procedure would better guide treatments in such patients.

\section{Abstract}

Objective: This study aimed to compare the answers given to the International Prostate Symptom score (IPSS) questionnaire by patients with the help of a physician according to age and education level.

Materials and Methods: The study included 204 patients, aged 50-75 years, who presented for the first time at the Urology Department with complaints of lower urinary tract symptoms and had not previously completed an IPSS form. The patients were given IPSS questionnaires and asked to complete them. Then the patients completed the IPSS forms again with the help of their physicians. The results were compared statistically. Results: When the education level was assessed separately, a significant difference was observed regarding the IPSS form completed with the help of a physician $(p<0.001)$. When the patients were divided by age as $<60$ years and $\geq 60$ years, a statistically significant difference was seen in the IPSS values $(p<0.001)$.

Conclusion: Regardless of age and education level, a difference was found between filling the IPSS form with the assistance of a physician and by patients alone. Clinicians should consider this situation.

Keywords: Benign prostate hyperplasia, IPSS, questionnaire forms

\section{Introduction}

The appropriate application of certain algorithms, and the quantification of these, are extremely crucial in the diagnosis, treatment, and follow-up of diseases for both the patient and physician. Several questionnaires have been created for this purpose and are used worldwide (1). The use of the International Prostate Symptom score (IPSS), is recognised as a symptom index for benign prostate hyperplasia (BPH). The IPSS has been approved as a questionnaire for the evaluation of lower urinary tract symptoms (LUTS) in males with BPH (2). Although these types of questionnaires are extremely beneficial in medical practice, the educational level of the patient, ability to understand the questions on the form, age, and mental state when completing the form can contribute in the mathematical differences, and this can change the form of treatment (3). This study aimed to evaluate the relationship between the age and educational level of the patient and IPSS scores when the form is completed alone or with the assistance of a physician.

Correspondence: Hasan Turgut MD, Faculty of Health Science, Avrasya University, Trabzon, Turkiye

Phone: +90 5059345825 E-mail: drhasanturgut@hotmail.com ORCID-ID: orcid.org/0000-0001-9793-6734

Received: 15.08 .2020

Accepted: 07.12. 2020

Cite this article as: Turgut H, Özgür GK. The Effective Way in Answering the IPSS: Patients Themselves or with the Physician? J Urol Surg 2021;8(1):46-49.

${ }^{\circ}$ Copyright 2020 by the Association of Urological Surgery / Journal of Urological Surgery published by Galenos Publishing House. 


\section{Materials and Methods}

After the institutional review board approval was obtained (Karadeniz Technical University Ethics Committee approval no: 2019/334), the prospective study enrolled 204 patients, aged 5075 years, who presented for the first time at the Urology with complaints of LUTS and had not previously completed an IPSS form. The patients were classified by age ( $<60$ and $\geq 60$ years) and by educational level (primary school, middle school, high school, and university). The patients were given the IPSS forms, for which the Turkish translation has been confirmed, and were instructed to complete it on their own, without help. Moreover, uroflowmetry was done to all patients who participated in the study. Voided urine with volumes $\geq 150 \mathrm{~mL}$ was used for the study. Qmax values $>15 \mathrm{~mL} / \mathrm{s}$ were excluded. To avoid bias, the physician did not evaluate the uroflowmetry and IPSS scores before the patients filled the forms alone.

Further, the IPSS form was completed with the assistance of a physician (a single physician, $\mathrm{HT}$, for all cases), and the time taken was recorded. Statistical analysis was conducted to determine differences between the results of IPSS questionnaires completed by the patient alone and those of forms completed with the help of the physician according to the age and educational level classifications.

Patients were excluded from the study if they had any lower urinary tract infection, ureteral stricture, a history of urinary system surgery, diabetes mellitus, and urinary malignancy or if they had previously completed an IPSS questionnaire.

\section{Statistical Analysis}

To assess the normal distribution, all continuous variables were analysed with the Kolmogorov-Smirnov test and histogram. The Wilcoxon-Rank test was used to compare the variables. Data obtained in the study were analysed statistically using SPSS for Windows vn 20.0 software ( SPSS, Chicago, IL, USA).

\section{Results}

The mean age of the whole patient group was 61.6 years. The educational level was determined to be high school and university in $62(30.3 \%)$ cases, middle school in $82(40.1 \%)$, and primary school in 60 (29.4\%) (Table 1). When the patients alone completed the IPSS, the mean scores for the subgroups of primary school, middle school, and high school and above were $14.8 \pm 1.7,16.0 \pm 1.1$, and $17.5 \pm 1.4$, respectively. When the IPSS was completed with the assistance of the physician, the mean scores for the subgroups of primary school, middle school, and high school and above were $21.2 \pm 3.1,21.3 \pm 2.5$, and $18.5 \pm 1.8$ respectively. A statistically significant difference was found between all the groups as regards the IPSS score $(p<0.001)$.
When classified according to age, the IPSS values of patients aged $<60$ years were $16.4 \pm 2$ when the questionnaire was completed alone and $19.7 \pm 2.9$ when completed with the assistance of a physician. For patients aged $>60$ years, the IPSS values were $15.9 \pm 1.5$ when the questionnaire was completed alone and $21.0 \pm 2.5$ when completed with the assistance of a physician. The difference between the two age groups was determined to be statistically significant $(p<0.001)$ (Table 2$)$. The mean quality of life score according to the urinary symptoms in item 8 of the IPSS was determined to be 2.6 when completed by the patient alone and 2.8 when completed with assistance from the physician. The mean time taken to complete the form with the assistance of the physician was 4.20 mins. The mean uroflowmetry values of the patients are summarised in Table 3.

\begin{tabular}{|l|l|l|l|l|}
\hline \multicolumn{5}{|l|}{ Table 1. Education level and IPSS values } \\
\hline $\begin{array}{l}\text { Education } \\
\text { level }\end{array}$ & $\begin{array}{l}\text { Number } \\
\text { (n) }\end{array}$ & $\begin{array}{l}\text { Patient IPSS } \\
\text { (mean } \pm \text { SD) }\end{array}$ & $\begin{array}{l}\text { Doctor IPSS } \\
\text { (mean } \pm \text { SD) }\end{array}$ & p-value \\
\hline Primary & $60(29.4 \%)$ & $14.8 \pm 1.7$ & $21.2 \pm 3.1$ & $<0.001$ \\
\hline Middle & $82(40.2 \%)$ & $16.0 \pm 1.1$ & $21.3 \pm 2.5$ & $<0.001$ \\
\hline $\begin{array}{l}\text { High and } \\
\text { above }\end{array}$ & $62(30.4 \%)$ & $17.5 \pm 1.4$ & $18.5 \pm 1.8$ & $<0.001$ \\
\hline SD: Standard deviation, IPSS: International Prostate Symptom score \\
\hline
\end{tabular}

\begin{tabular}{|l|l|l|l|l|}
\hline \multicolumn{6}{|l|}{ Table 2. IPSS values by age } \\
\hline Age & Number (\%) & Patient IPSS & Doctor IPSS & p-value \\
\hline$<60$ & $82(40.1 \%)$ & $16.4 \pm 2$ & $19.7 \pm 2.9$ & $<0.001$ \\
\hline$\geq 60$ & $122(59.9 \%)$ & $15.9 \pm 1.5$ & $21 \pm 2.6$ & $<0.001$ \\
\hline IPSS: International Prostate Symptom score
\end{tabular}

\begin{tabular}{|c|c|}
\hline Uroflowmetry & mean \pm SD \\
\hline Voided volume (mL) & $183.0 \pm 69.7$ \\
\hline Maximum flow rate $(0 \max , \mathrm{mL} / \mathrm{s})$ & $13.2 \pm 14.4$ \\
\hline Mean voiding time (second) & $52.7 \pm 19.1$ \\
\hline Flow time (second) & $41.0 \pm 13.2$ \\
\hline Average flow rate (Qave) & $5.6 \pm 3.4$ \\
\hline Time to maximum flow (second) & $9.8 \pm 4.9$ \\
\hline
\end{tabular}

\section{Discussion}

Just as in several different branches, several questionnaires are used in urology practice. One of these forms, which was created after extremely extensive studies and was prepared to be short and clear and in a concise language, is the IPSS questionnaire which is used in BPH diagnosis and is the most commonly used form in urology practice. The IPSS has been translated into several languages and has started to be used in other countries (4). Seven items are related to bladder capacity and urination 
symptoms. The symptom scores are classified as mild degree, 1-7 points; moderate, 8-19 points; and severely symptomatic, 20-35 points (5). Item 8 of the IPSS is related to quality of life; previous studies have shown that quality of life is the most significant predictor of improvement with treatment (6).

Studies conducted after the IPSS came into use have reported it to be a simple and reliable evaluation method not affected by educational level and sociodemographic variables $(1,7)$. However, observations in our clinic have shown that several patients have difficulty in completing the IPSS questionnaire and the level of treatment is affected by the IPSS score. Therefore, this study aimed to classify patients according to age and educational level and show the effect of assistance from the physician on IPSS scores.

A study by Cam et al. (8) revealed that patients with a primary school educational level did not fully complete the IPSS questionnaire. Moreover, Van der Walt et al. (9) reported that when the educational level of the patient was low, more help was needed to complete the IPSS. In contrast, Netto Júnior and de Lima (10) reported that educational level had no effect on IPSS scores; however, in the study, the patients were given information regarding the questions and how to answer them before they completed the questionnaire.

This approach may have affected the results, especially for the group of patients with a low education level. In another study conducted in Portugal and Brazil, a significantly low rate of form completion by the group with a low education level was noted. Bozlu et al. (11) demonstrated that educational level did not affect the IPSS and QOL results when the questionnaire was administered either by the physician or patient alone. In the current study, when the evaluation was made according to the classification of primary school, middle school, and high school and above level of education, although all the groups completed the form fully, the IPSS results were statistically significant when the form was completed with the assistance of the physician.

In a study by Johnson et al. (12), majority of the patients completed the form on their own, and it was determined that majority of them were young and with a high level of income. In the current study, the income level was not examined; however, the mean IPSS value was found to be higher in the patient group aged $<60$ years compared to those aged $>60$ years. This result can be attributed to a higher level of education in the younger group.

When the different ethnic origins of those living in a society are considered, several people with different native languages living in different countries can be seen. Even if questionnaires such as the IPSS are translated into different languages, it may not be completely translated into the native language of the individual, and this could imply a controversy on the extent to which the patient has understood the questions, and correct responses may not be given. Despite the high education level of many people, words used in the original IPSS form are not frequently encountered and routinely used words (13). Although the IPSS is better understood and completed as education level of the respondent increases, the accuracy of the responses may not always be guaranteed. The reason for the difference seen between all the education level groups in the current study could be due to this.

One of the questions which was difficult to understand and interpret for patients is the question on quality of life according to urinary symptoms. Words such as "pleased", "delighted", and "happy" may not be clearly defined in local languages. However, in the current study, the quality of life values according to urinary symptoms were similar when the patient completed the form alone and with the assistance of the physician.

Due to an intense work tempo and patient numbers, several urologists avoid completing the IPSS together with the patient. In literature, there is no report that provides information about the time taken to complete the IPSS. In the current study, as there was the uncertainty that a true result could be obtained from timing the patient completing the form alone, only the time taken to complete the form together with the physician was recorded, and a mean time of 4.20 mins was determined. This can be considered an extremely short time to ensure the correct diagnosis and treatment for a BPH patient.

\section{Study Limitations}

This study had some limitations, primarily its small sample size. Additionally, because of the range of ethnicities, there may have been difficulties for some patients in understanding the IPSS as it was completed in the frequently spoken language rather than their native language. To be able to complete the form correctly, it is crucial to correctly understand the questions first. Although factors such as age and education level have an effect on understanding the questionnaire correctly, they are not sufficient, and the cognitive capacity of the patient should be evaluated. In the current study, cognitive capacity was not assessed. With a correct scale, further extensive studies could provide objective results.

Additionally, although it is clear from the results of the study that assistance increases the IPSS score, it cannot be concluded that these higher IPSS scores obtained by the help of physician show clinical symptoms better than self-filled scores. Further studies evaluating the correlations between Omax, post-void residual, etc., should be conducted to reveal the correctness of each method. 


\section{Conclusion}

When it is considered that the IPSS was completed by the physician in a short time, it can be deduced that irrespective of age and educational level, completion of the form together with the physician can result in accurate diagnosis and treatment. In addition, the translation of questionnaires such as the IPSS into concise and understandable language and various local languages could increase accuracy rates.

\section{Ethics}

Ethics Committee Approval: After the institutional review board approval was obtained (Karadeniz Technical University Ethics Committee approval no: 2019/334).

Informed Consent: Informed written consent was obtained from all patients before participating in the study.

Peer-review: Externally peer-reviewed.

\section{Author Contributions}

Concept: H.T., Design: H.T., G.K.Ö., Data Collection and/or Processing: H.T., G.K.Ö., Analysis and/or Interpretation: G.K.Ö., Literature Search: H.T., Writing: H.T., Critical Review: G.K.Ö.

Conflict of Interest: The authors have no conflicts of interest to declare.

Financial Disclosure: The authors declared that this study has received no financial support.

\section{References}

1. Barry MJ. Evaluation of symptoms and quality of life in men with benign prostatic hyperplasia. Urology 2001;58:25-32.

2. Netto Junior NR, de Lima ML. The influence of patient education level on the International Prostatic Symptom Score. J Urol 1995;154:97-99.
3. Badia X, Rodríguez F, Carballido J, Garcia Losa M, Unda M, Dal-Ré R, Roset M; ESECI-98 Group. Influence of sociodemographic and health status variables on the American Urological Association symptom scores in patients with lower urinary tract symptoms. Urology 2001;57:71-77.

4. Badia $X$, Garcia-Losa $M$, Dal-Ré R. Ten-language translation and harmonization of the International Prostate Symptom Score: developing a methodology for multinational clinical trials. Eur Urol 1997;31:129-140.

5. Reohrborn GC. Beningn prostatic hyperplasia: etiology, pathophysiology, epidemiology, and natural history. In: Kavaoussi LR, Novick AC, Partin AW, Peters CA, editors. Campbell-Wash urology. 10th ed. Philadelphia: Saunders Esavier; 2012. p. 2576-2581.

6. Barry MJ, Girman CJ, O'Leary MP, Walker-Corkery ES, Binkowitz BS, Cockett AT, Guess HA; The Benign Prostatic Hyperplasia Treatment Outcomes Study Group. Using Repeated Measures of Symptom Score, Uroflowmetry and Prostate Specific Antigen in the Clinical Management of Prostate Disease. J Urol 1995;153:99-103.

7. Moon TD, Brannan W, Stone NN, Ercole C, Crawford ED, Chodak G, Brawer M, Heisey D, Bruskewitz RC. Effect of age, educational status, ethnicity and geographic location on prostate symptom scores. J Urol 1994;152:14981500.

8. Cam K, Senel F, Akman Y, Erol A. The efficacy of an abbreviated model of the International Prostate Symptom Score in evaluating benign prostatic hyperplasia. BJU Int 2003;91:186-189.

9. Van der Walt $C L$, Heyns $C F$, Groeneveld $A E$, Edlin RS, van Vuuren SP. Prospective comparison of a new visual prostate symptom score versus the international prostate symptom score in men with lower urinary tract symptoms. Urology 2011;78:17-20.

10. Netto Júnior NR, de Lima ML. The influence of patient education level on the International Prostatic Symptom Score. J Urol 1995;154:97-99.

11. Bozlu M, Doruk E, Akbay E, Ulusoy E, Cayan S, Acar D, Kanik EA. Effect of administration mode (patient vs physician) and patient's educational level on the Turkish version of the International Prostate Symptom Score. Int J Urol 2002;9:417-421.

12. Johnson TV, Goodman M, Master VA. The efficacy of written screening tools in an innercity hospital: literacy based limitations on patient access to appropriate care. J Urol 2007;178:623-629.

13. MacDiarmid SA, Goodson TC, Holmes TM, Martin PR, Doyle RB. An assessment of the comprehension of the American Urological Association Symptom Index. J Urol 1998;159:873-874. 